\title{
FRAZIL FORMATION IN WATER OF DIFFERENT SALINITIES AND SUPERCOOLINGS
}

\author{
By GEE TSANG \\ (Hydraulics Division, National Water Research Institute, Canada Centre for Inland Waters, Burlington, Ontario L7R 4A6, Canada) \\ and THOMAS O'D. HANLEY, S.J.
}

(Campion College, University of Regina, Regina, Saskatchewan S4S 0A2, Canada)

\begin{abstract}
The formation of frazil in water of different salinities and initial supercoolings was studied in the laboratory. Experiments were conducted both on genuine and artificial sea-waters. From analysing the experimental results, it was found that the production rate of frazil is highly sensitive to the initial supercooling of the water and will increase over three orders of magnitude as the initial supercooling increases from zero to $2^{\circ} \mathrm{C}$. By properly non-dimensionalizing the parameters, it was found that the normalized concentration of frazil in water is principally a function of the normalized time. For the rate of production of frazil, however, it was found that the normalized rate of frazil production, besides being a function of the normalized time, is also affected by the salinity and the initial supercooling of the water. Different frazil crystals formed in water of different salinities and initial supercoolings are thought to be the reason for the different curves of frazil production rate. The normalization of parameters requires the determination of some characteristic parameters which were found to be well-defined functions of initial supercooling and salinity.
\end{abstract}

RÉsumÉ. Formation de frazil dans des eaux de différentes salinités et surfusion. Le formation de frazil dans des eaux de différentes salinités et surfusion initiales a été étudiée en laboratoire. Des expériences ont été réalisées à la fois avec des eaux de mer naturelles et artificielles De l'analyse des résultats expérimentaux on trouve que la vitesse de production du frazil est très sensible à la surfonte initiale et qu'elle croît de trois ordres de grandeur quand la surfusion initiale passe de zéro à $2^{\circ} \mathrm{C}$. En passant à des paramètres sans dimensions convenables, on a trouvé que la concentration normalisée de frazil dans l'eau est principalement une fonction du temps normalisé. Quant au taux de formation de frazil cependant, on a trouvé que la

\section{Time}

$t_{c}$

$t_{\min } \quad$ time when the water reached its minimum temperature.

$t_{n} \quad$ time of beginning of nucleation of the supercooled water.

$\mathrm{t}_{*}=\mathrm{t} / \mathrm{t}_{\mathrm{c}} \quad$ dimensionless time.

$\Delta \mathrm{t}$ increment of dimensionless time.

\section{Temperature}

$\mathrm{T}_{\mathrm{e}}$

equilibrium temperature between frazil and ice-producing water.

freezing temperature of water. vitesse de formation normalisée, bien qu'elle soit fonction du temps normalisé est aussi affectée par la salinité et le degré de surface initial de l'eau. Les différentes cristaux de frazil formés dans l'eau de différentes salinités et différentes surfusions initiales sont rendus responsables des différentes vitesses de production du frazil. La normalisation des paramètres requiert la détermination de quelques paramètres caractéristiques qui ont été trouvés être des fonctions bien définies de la surfusion et salinité initiales.

Zusammenfassung. Die Bilding freischwebender Eiskristalle in Wasser verschiedener Salinität und Unterkühlung. Die Bildung von freischwebenden Eiskristallen in Wasser verschiedener Salinität und Ausgangsunterkühlung wurde im Labor untersucht. Die Versuche wurden sowohl mit echtem wie mit künstlichem Meerwasser vorgenommen. Aus der Analyse der Versuchsergebnisse war zu sehen, dass die Produktionsrate von freischwebenden Eiskristallen ausserordentlich empfindlich gegenüber der Ausgangsunterkühlung des Wassers ist und um drei Grössenordnungen wåchst, wenn die Ausgangsunterkühlung von $0^{\circ} \mathrm{C}$ auf $2{ }^{\circ} \mathrm{C}$ ansteigt. Bei geeigneter Dimensionierung der Parameter ergab sich, dass die normalisierte Konzentration von freischwebenden Eiskristallen in Wasser grundsätzlich eine Funktion der normalisierten Zeit ist. Doch zeigt sich, dass die normalisierte Rate der Kristallproduktion ausserdem durch die Salinität und die Ausgangsunterkühlung des Wassers beeinflusst wird. Verschiedene Kristalle, entstanden in Wasser verschiedener Salinität und Ausgangsunterkühlung, werden als Grund für die Unterschiede in den Kurven der Kristall-Produktionsraten angenommen. Die Normalisierung der Parameter erfordert die Bestimmung einiger charakteristischer Parameter, die sich als wohldefinierte Funktionen der Ausgangsunterkühlung und der Salinität erweisen.

$$
\begin{array}{ll}
\mathrm{T}_{\min } & \begin{array}{l}
\text { minimum temperature. } \\
\mathrm{T}_{\mathrm{n}}
\end{array} \\
\overline{\mathrm{T}} & \begin{array}{l}
\text { water temperature at which ice begins to } \\
\text { nucleate. }
\end{array} \\
(\mathrm{dT} / \mathrm{dt})_{\mathrm{n}} \quad \begin{array}{l}
\text { spatial average of the water temperature. } \\
\text { the time } \mathrm{t}_{\mathrm{n}}
\end{array} & \\
\Delta \mathrm{T}=\mathrm{T}_{\mathrm{f}}-\overline{\mathrm{T}} & \\
\Delta \mathrm{T}_{\min }=\mathrm{T}_{\mathrm{f}}-\mathrm{T}_{\min } \\
\Delta \mathrm{T}_{\mathrm{n}}=\mathrm{T}_{\mathrm{f}}-\mathrm{T}_{\mathrm{n}} \\
\Delta \mathrm{T}_{\mathrm{s}}=\mathrm{T}_{\mathrm{n}}-\mathrm{T}_{\min } \\
\Delta \mathrm{T}_{*}=\Delta \mathrm{T} / \Delta \mathrm{T}_{\min } \text { dimensionless increment of temperature. }
\end{array}
$$




\section{Concentration}

$\mathrm{c}_{\mathrm{i}}$

$\overline{\mathrm{c}}_{\mathrm{i}}$

$\overline{\mathrm{c}}_{\mathrm{ic}}$

concentration of frazil in water by weight.

spatial average of $c_{i}$.

characteristic concentration of frazil;

the concentration at time $t_{c}$.

$\bar{c}_{i_{*}}=\bar{c}_{\mathrm{i}} / \bar{c}_{\mathrm{i}} \quad$ normalized spatial average concentration of frazil in water.

$\overline{\mathrm{d}} \overline{\mathrm{i}}_{\mathrm{i}} / \mathrm{dt}=\left(\mathrm{c}_{\mathrm{ic}}-\overline{\mathrm{c}}_{\mathrm{imin}}\right) /\left(\mathrm{t}_{\mathrm{c}}-\mathrm{t}_{\min }\right)$ average rate of frazil production.

$\mathrm{dc}_{\mathrm{i}_{*}} / \mathrm{dt}{ }_{*} \quad$ dimensionless rate of frazil production.

\section{Other quantities}

A

area of bounding surface of the control volume. c

$c_{0}$

$\mathrm{H}_{\mathrm{L}}$

$\hat{\mathrm{n}}$

$\vec{q}$

r

$\mathrm{R}^{2}$

V

p specific heat of the water.

specific heat of fresh water.

latent heat of fusion of ice.

normal unit vector pointing away from the bounding surface of the control volume.

heat-flux vector.

coefficient dependent on salinity, such that $\mathrm{c}=\mathrm{rc}_{0}$.

coefficient of determination.

control volume.

density of the water or brine.

estimate of standard deviation.

\section{INTRODUCTION}

In turbulent rivers, lakes, and seas, the ice formed is in the form of fine crystals suspended in the water and is known as frazil. The formation, evolution, properties and effects of fresh-water and sea-water frazil have been summarized by the review papers by Osterkamp (1978) and Martin (1981) and the monograph by Tsang (1982). As a whole, human knowledge on frazil is still meagre and much more has yet to be learned.

Figure 1 shows a typical temperature-time curve of frazil-producing water in which the vertical axis denotes the spatial average temperature $\bar{T}$ of the control volume. From this graph much can be learned. It is seen from Figure 1 that for water of a given salinity, there exists a freezing temperature $T_{f}$. As the ice-free water is cooled to below $T_{f}$ it becomes supercooled and is capable of producing ice. If at temperature $T_{n}$ ice starts to form (nucleation is sometimes artificially initiated by seeding, that is by introducing suitable nuclei to the supercooled water), then the latent heat of fusion of ice will be liberated and the temperature curve will show an upward departure from the pre-seeding cooling curve. At the minimum temperature point $T_{\min }$, the rate of latent heat liberation is equal to the rate of heat loss to the environment. After $\mathrm{T}_{\min }$, the temperature curve begins to climb until the equilibrium temperature $T_{e}$ is reached. The equilibrium temperature $\mathrm{T}_{\mathrm{e}}$ is slightly less than the freezing temperature $T_{f}$ and their difference $\left(\mathrm{T}_{\mathrm{f}}-\mathrm{T}_{\mathrm{e}}\right)$ is known as the residual temperature and is the driving force to remove heat from the surface of the frazil crystals if frazil is continuing to form. For the convenience of the reader, a list of symbols used in this paper is included at the beginning of the paper.

The period of frazil production after $T_{e}$ is reached is called the equilibrium period. The period from $T_{n}$ to the time when $T_{e}$ is reached is called the initial period.

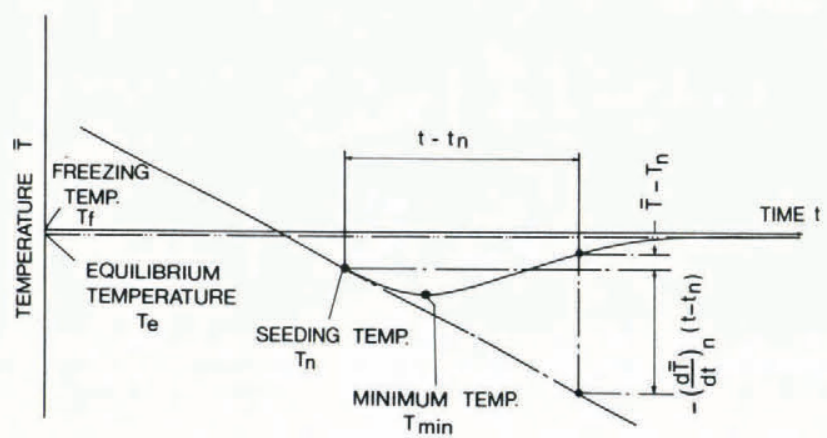

Fig. 1. Typical time-temperature curve of frazil-producing water.

Because the point at which the temperature first reaches $T_{e}$ is difficult to ascertain, for better definition the terminating point of the initial period may be chosen to be the point where a convenient percentage (say 90\%) of the temperature depression $\left(\mathrm{T}_{\mathrm{e}}-\mathrm{T}_{\min }\right)$ has been recovered. In the equilibrium period, the rate of frazil formation is governed by the rate of heat loss to the ambient environment. In the initial period, however, the rate of frazil formation is affected by many factors including the degree of supercooling, the salinity of water, the level of turbulence, etc., in addition to the rate of heat loss. It is important to study the quantitative effects of these parameters on the formation of frazil because the fast change of flow characteristics, the formation of anchor ice and the blockage of underwater water intakes, the production of fresh water from sea-water by desalination using the freezing method, and many other engineering and industrial applications and processes all involve the initial period of $\mathrm{frazil}$ formation.

Hanley and Tsang (1984) have studied the supercooling effect on the formation of frazil in highly saline water. Their water was artificially prepared by dissolving "Forty Fathoms"* in distilled water and had a salinity of $48.1 \%$ (parts per thousand). They found that the average rate of frazil formation in the initial period, using the $90 \%$ temperature depression recovery point as the end of the period, is a well-defined function of supercooling at seeding. When the degree of supercooling was increased from 0 to $2 \mathrm{deg}$, which was the upper limit of supercooling of the experiments, the rate of frazil formation increased dramatically by over three orders of magnitude.

In this paper, experiments similar to those by Hanley and Tsang (1984) on water of reduced salinities will be reported. The experimental results will be examined to see whether functional relationships between the rate of frazil production and supercooling similar to those obtained by the above researchers can be obtained over the whole range of salinities.

There has been debate on the crystallographic shape of frazil crystals. Although most researchers seemed to agree that fresh-water frazil is composed mostly of

* "Forty Fathoms" is a chemical produced by Marine Enterprises, Timonium, Maryland, U.S.A., for salt-water aquaria. When dissolved in fresh water until a specific gravity of 1.0250 is obtained, the solution will have the following major elements: $\mathrm{Cl} 18.6 \%$ oo, Na $10.4 \%$ oo, $\mathrm{SO}_{4} 2.6 \%$, Mn $1.3 \%$, Ca $0.41 \%$, 00 , $0.38 \%$, and other minor elements that are typical of sea-water. The recommended specific gravity of the solution for aquarium use is 1.0201 . 
discoid crystals but, under certain still not well understood conditions, needle crystals and flake crystals can also be found, their opinions on saline water frazil were not at all unanimous. By conducting experiments on salt $(\mathrm{NaCl})$ solution in water, Martin and Kauffman (1981) reported discoid saline-water frazil crystals. D Calkins (personal communication in 1982) also observed discoid frazil crystals in his experiments for which the saline water was artificially prepared by dissolving urea in water. By using genuine sea-water and a new photographic technique, Tsang (1983) conducted a series of experiments and found that although fresh-water frazil is indeed mostly composed of discoid crystals, the sea-water frazil crystals are mostly of two shapes; the Christmas star shape and the three-dimensional thorn-ball shape. Because the crystallographic shapes of genuine sea-water frazil and artificial sea-water frazil, and possibly their properties and behaviour, are different, the question is raised as to whether laboratory experiments using artificial sea-water may be conducted to investigate problems involving actual sea-water.

To answer the above question, the experimental results of Tsang (1983) and Hanley and Tsang (1984) and the experiment series conducted for this paper will be compared. From the comparison, one can at least tell whether or under what limitations "Forty Fathoms" solution may be used as simulated sea-water in laboratory investigations.

In treating his data, Tsang was able to show that by properly non-dimensionalizing the parameters, the curves of frazil concentration versus time for all his experiments could be condensed into one. In this paper, the experimental results of Hanley and Tsang and the experimental results of the experiment series for this paper will be similarly treated to see whether single curves can be obtained for the artificial sea-water experiments with different salinity. By comparing these curves among themselves and with that obtained by Tsang, one can see the effect of salinity on the normalized concentration-time curve and how well artificial sea-water may be used to simulate genuine sea-water.

In this paper, the non-dimensional rate of frazil production for the three groups of experiments mentioned will also be evaluated and plotted against time. From these curves showing the normalized rate of frazil production versus time one will be able to see: 1 . for a given salinity and supercooling, how the rate of frazil production varies with time; 2. for a given salinity, how supercooling affects the rate of production of frazil; 3. how salinity affects the curve for the rate of frazil production; and 4. how accurately artificial sea-water can simulate true sea-water in studying the rate of production of frazil.

\section{THEORY}

For a control volume, if the concentration of frazil in it is small and if there is no mass transfer across its boundary, the equation for the conservation of heat may be written as (Tsang, 1982)

$$
\int_{V} \rho H_{L} \frac{\partial c_{i}}{\partial t} d V-\int_{V} \rho \frac{\partial T}{\partial t} d V-\phi \vec{q} \cdot \hat{n} d A=0
$$

where $c_{i}$ is the point concentration of frazil in the frazil-water mixture by weight, $\mathrm{V}$ is the control volume, $A$ is the area of the bounding surface, $\rho, T$, and $c$ are the density, temperature at a point, and the specific heat of water respectively, $\mathrm{H}_{\mathrm{L}}$ is the latent heat of fusion of ice, $t$ is time, $\vec{q}$ is the heat flux vector, and $\hat{n}$ is the normal unit vector pointing away from the bounding surface. The first integral in the above equation is the rate of release of latent heat because of frazil formation, the second integral represents the rate of heat absorption by the water to increase its temperature, and the third integral is the total rate of heat loss to the outside as heat leaves the control volume across its boundary. Using spatial average values, the above equation may be rewritten as

$$
\rho \mathrm{VH}_{\mathrm{L}} \frac{\mathrm{d} \overline{\mathrm{i}}}{\mathrm{dt}}-\rho \mathrm{cV} \frac{\mathrm{d} \overline{\mathrm{T}}}{\mathrm{dt}}-\oint \overrightarrow{\mathrm{q}} \cdot \hat{\mathrm{n}} \mathrm{dA}=0 .
$$

Before the formation of frazil, there is no ice in the control volume so that the first term in the above equation vanishes. If, in addition, the ambient environment and the flow characteristics change little during the frazil-producing period, then the rate of heat loss to the outside may be considered to be approximately constant and given by

$$
\oint \vec{q} \cdot \hat{n} d A=-\rho c V\left(\frac{d \bar{T}}{d t}\right]_{n}
$$

where the subscript $\mathrm{n}$ indicates the moment just before seeding, or for most practically important cases, the moment of seeding. The substitution of the above equation in Equation (2) and subsequent integration give

$$
\bar{c}_{i}=\frac{c}{H_{L}}\left[-\left[\frac{d \bar{T}}{d t}\right]_{n}\left(t-t_{n}\right)+\left(\bar{T}-T_{n}\right)\right] .
$$

The quantity inside the square brackets on the right of the above equation is represented in Figure 1 by the vertical distance between the point on the extension of the pre-seeding straight-line cooling curve at time $t$, and the point on the graph of water temperature at time $t$ Thus, knowing the time-temperature curve, the concentration of frazil at different instants can be calculated.

Although the concentration of frazil can be calculated from Equation (4) knowing the time-temperature curve, Hanley and Tsang showed that for frazil produced under different parametric conditions, even with the same salinity, the time-temperature curves can be very different. The concentration curve calculated from these time-temperature curves therefore can also be vastly different and this imposes a severe limitation on their application to solve practical problems. Tsang showed that the above difficulty can be overcome by non-dimensionalizing the parameters involved as shown below. With such a normalization, the curves of frazil concentration versus time for all his experiments on genuine sea-water were condensed into a single curve. It remains to be seen whether the same is true for experiments using artifical sea-water of different salinites.

With reference to Figure 1, if one defines

$\Delta \mathrm{T}=\mathrm{T}_{\mathrm{f}}-\overline{\mathrm{T}}, \quad \Delta \mathrm{T}_{\min }=\mathrm{T}_{\mathrm{f}}-\mathrm{T}_{\min }, \quad \Delta \mathrm{T}_{\mathrm{s}}=\mathrm{T}_{\mathrm{n}}-\mathrm{T}_{\min }$,

introduces a characteristic time $t_{c}$, and considers the time of seeding as time zero, then Equation (4) may be rewritten as

$$
\begin{aligned}
\bar{c}_{\mathrm{i}}=\frac{\mathrm{c} \Delta \mathrm{T}_{\min }}{\mathrm{H}_{\mathrm{L}}} & {\left[-\left[\frac{\mathrm{d} \overline{\mathrm{T}}}{\mathrm{dt}}\right]_{\mathrm{n}} \frac{\mathrm{t}_{\mathrm{c}}}{\Delta \mathrm{T}_{\min }} \frac{\mathrm{t}}{\mathrm{t}_{\mathrm{c}}}-\right.} \\
& \left.-\frac{\Delta \mathrm{T}}{\Delta \mathrm{T}_{\min }}-\frac{\Delta \mathrm{T}_{\mathrm{s}}}{\Delta \mathrm{T}_{\min }}+1\right],
\end{aligned}
$$

Let $t_{c}$ be the time when $90 \%$ of the maximum temperature depression is recovered; then

at $\quad \mathrm{t}=\mathrm{t}_{\mathrm{c}}, \frac{\Delta \mathrm{T}}{\Delta \mathrm{T}_{\text {min }}}=0.1$, 
and

$$
\begin{aligned}
\bar{c}_{\mathrm{i}}=\overline{\mathrm{c}}_{\mathrm{i}\left(\mathrm{t}_{\mathrm{c}}\right)=\overline{\mathrm{c}}_{\mathrm{ic}}=\frac{\mathrm{c} \Delta \mathrm{T}_{\min }}{\mathrm{H}_{\mathrm{L}}}}\left[-\left[\frac{\mathrm{d} \overline{\mathrm{T}}}{\mathrm{dt}}\right]_{\mathrm{n}} \frac{\mathrm{t}_{\mathrm{c}}}{\Delta \mathrm{T}_{\min }}+\right. \\
\left.+0.9-\frac{\Delta \mathrm{T}_{\mathrm{S}}}{\Delta \mathrm{T}_{\min }}\right],
\end{aligned}
$$

The non-dimensional time, supercooling and concentration may now be defined as

$\mathrm{t}_{*}=\mathrm{t} / \mathrm{t}_{\mathrm{c}}, \quad \Delta \mathrm{T}_{*}=\Delta \mathrm{T} / \Delta \mathrm{T}_{\min }$, and $\overline{\mathrm{c}}_{\mathrm{i}_{*}}=\overline{\mathrm{c}}_{\mathrm{i}} / \overline{\mathrm{c}}_{\mathrm{ic}}$.

With the above definitions, Equation (6) may be rewritten in the form

$\overline{\mathrm{c}}_{\mathrm{i} *}=\frac{\left[-\left[\frac{\mathrm{d} \overline{\mathrm{T}}}{\mathrm{dt}}\right]_{\mathrm{n}} \frac{\mathrm{t}_{\mathrm{c}}}{\Delta \mathrm{T}_{\min }} \mathrm{t}_{*}+1-\Delta \mathrm{T}_{*}-\frac{\Delta \mathrm{T}_{\mathrm{s}}}{\Delta \mathrm{T}_{\min }}\right]}{\left[-\left[\frac{\mathrm{d} \overline{\mathrm{T}}}{\mathrm{dt}}\right)_{\mathrm{n}} \frac{\mathrm{t}_{\mathrm{c}}}{\Delta \mathrm{T}_{\min }}+0.9-\frac{\Delta \mathrm{T}_{\mathrm{s}}}{\Delta \mathrm{T}_{\min }}\right]}$.

It was according to the above equation that Tsang plotted his experimental data from nine experiments and obtained a single mean curve. It should be noted, however, that Tsang's plotting showed some scatter of experimental data from the mean curve so a single mean curve can only be accepted if one is prepared to accept a certain degree of error when using the mean curve in design.

When applying the normalized curve to solve practical design problems, the non-dimensional variables $\bar{c}_{i *}$ and $t *$ obtained from the curve have to be eventually converted back into the dimensional form. According to Equation (8), this requires knowledge of the characteristic parameters $\bar{c}_{i c}$ and $t_{c}$. To evaluate $\bar{c}_{i c}$, according to Equation (7), one in turn needs to know $\mathrm{t}_{\mathrm{c}}, \Delta \mathrm{T}_{\min }, \Delta \mathrm{T}_{\mathrm{s}}$, and $(\mathrm{dT} / \mathrm{dt})_{\mathrm{n}}$. Denoting the supercooling at seeding by

$$
\Delta \mathrm{T}_{\mathrm{n}}=\mathrm{T}_{\mathrm{f}}-\mathrm{T}_{\mathrm{n}},
$$

Tsang (1983) showed from his experiments that both $t_{c}$ and $\Delta \mathrm{T}_{\text {min }}$ are functions of $\Delta \mathrm{T}_{\mathrm{n}}$ alone. Since $\Delta \mathrm{T}_{\mathrm{s}}$ may be expressed as

$$
\begin{gathered}
\Delta T_{s}=T_{n}-T_{\min }=\left(T_{f}-T_{\min }\right)- \\
-\left(T_{f}-T_{n}\right)=\Delta T_{\min }-\Delta T_{n}
\end{gathered}
$$

so it also is a function of $\Delta T_{n}$ alone. Thus, according to the above, one sees that to evaluate $\bar{c}_{\mathrm{ic}}$, only $\Delta \mathrm{T}_{\mathrm{n}}$ and $(\mathrm{d} \overline{\mathrm{T}} / \mathrm{dt})_{\mathrm{n}}$ are needed. To sum up, one can say that knowing the supercooling and rate of cooling of the water at seeding, the characteristic parameters $t_{c}$ and $\bar{c}_{i c}$ can be calculated for converting the non-dimensional time and frazil concentration into the dimensional form.

Differentiating $\bar{c}_{j} *$ with respect to $t *$ gives

$$
\frac{\mathrm{dc}_{\mathrm{i}_{*}}}{\mathrm{dt}_{*}}=\frac{\left[-\left(\frac{\mathrm{d} \overline{\mathrm{T}}}{\mathrm{dt}}\right]_{\mathrm{n}} \frac{\mathrm{t}_{\mathrm{c}}}{\Delta \mathrm{T}_{\min }} \mathrm{t}_{*}+\frac{\mathrm{d}\left(\Delta \mathrm{T}_{*}\right)}{\mathrm{dt}_{*}}\right]}{\left[-\left[\frac{\mathrm{d} \overline{\mathrm{T}}}{\mathrm{dt}}\right]_{\mathrm{n}} \frac{\mathrm{t}_{\mathrm{c}}}{\Delta \mathrm{T}_{\min }}+0.9-\frac{\Delta \mathrm{T}_{\mathrm{S}}}{\Delta \mathrm{T}_{\min }}\right]}
$$

which gives the non-dimensional rate of frazil production in the water. In this paper, $\mathrm{dc}_{\mathrm{i}^{*}} / \mathrm{dt}^{*}$ will be plotted for the three groups of experiments and compared. It is hoped that through intercomparison, some regularity and the pattern of parametric effect may be detected.

When the time is large, the water temperature will approach the equilibrium temperature and $\mathrm{d}(\Delta \mathrm{T} *) / \mathrm{dt}$ * will approach zero. Under such a condition, Equation (12) is reduced to

$$
\begin{aligned}
& \frac{\mathrm{d}_{\mathrm{i}} *}{\mathrm{dt}_{*}}=\left[-\left(\frac{\mathrm{d} \overline{\mathrm{T}}}{\mathrm{dt}}\right]_{\mathrm{n}} \frac{\mathrm{t}_{\mathrm{c}}}{\Delta \mathrm{T}_{\min }}\right]\left[-\left[\frac{\mathrm{d} \overline{\mathrm{T}}}{\mathrm{dt}}\right]_{\mathrm{n}} \frac{\mathrm{t}_{\mathrm{c}}}{\Delta \mathrm{T}_{\min }}+\right. \\
& \left.+0.9-\frac{\Delta \mathrm{T}_{\mathrm{s}}}{\Delta \mathrm{T}_{\min }}\right]^{-1}
\end{aligned}
$$

which is constant.

\section{EXPERIMENTS AND EXPERIMENTAL DATA}

The results of three groups of experiments are studied in this paper; they are those conducted by Hanley and Tsang (1984) or Group A, those conducted especially for this paper by the authors or Group B, and those conducted by Tsang (1983) or Group C. The following subsections describe the experimental set-up, procedure, and experimental data of these three different groups of experiments.

\section{Group A experiments}

A total of eight experiments were conducted in this group of experiments. "Forty Fathoms" dissolved in distilled water was used as the artificial sea-water in the experiments. The specific gravity of the "Forty Fathoms" solution was about 1.036 and from this the salinity was calculated by Hanley and Tsang to be about $44 \%$. A recent check of their calculation, however, revealed that they had overlooked the temperature effect on the specific gravity. If the temperature effect were also considered, the salinity of the artificial sea-water would be modified to about $48 \%$. The experiments were conducted in a cold room in a Plexiglass tank measuring $38 \mathrm{~cm}$ long $\times 25.5 \mathrm{~cm}$ wide $\times 15 \mathrm{~cm}$ deep. The turbulence in the tank was produced by a stirrer mounted at one end of the tank. A horizontal plate three quarters the length of the tank and fixed at the mid depth of the tank helped to set up a vertical recirculating current in the tank with a velocity of approximately $15 \mathrm{~cm} / \mathrm{s}$. Under these conditions of flow and turbulence, the distribution of temperature in the tank was uniform. The tank was surrounded with a warm air jacket except at the surface, which was exposed to a cold air stream that was set up by a fan. The temperature of the warm air jacket was maintained slightly above freezing. The cold room was set at 15 deg below freezing for all the experiments. During the experiment, the water temperature was measured with a precision thermometer that could measure to a thousandth of a degree Celsius and had a repeatability of $0.001 \mathrm{deg}$, and the measured temperature was recorded on a strip chart. To produce frazil in the tank, the water was cooled to the pre-selected temperature, then the supercooled water was seeded either with a pea-sized lump of ice or with ice particles scraped from a slab of ice with a saw blade. The detailed experimental set-up and procedure were reporteed by Hanley and Tsang (1984). The parameters of the Group A experiments, including those obtained from the chart recordings, are summarized in Table I. It may be noted that in Table I the temperature depressions were calculated using the equilibrium temperature $\mathrm{T}_{\mathrm{e}}$ in place of the freezing temperature $\mathrm{T}_{\mathrm{f}}$. This is permissible because it was found experimentally for the present experiments that these two temperatures differed by only about $0.001 \mathrm{deg}$.

\section{Group B experiments}

Three series of experiments were conducted for this group. Series 1 consisted of six experiments for which the salinity of the water was about $23.0 \%$. Series 2 
TABLE I. PARAMETERS OF EXPERIMENTS

\begin{tabular}{|c|c|c|c|c|c|c|c|c|c|c|c|c|c|c|c|}
\hline $\begin{array}{l}\text { GROUP \& } \\
\text { SERTES }\end{array}$ & $\begin{array}{l}\text { Exp. } \\
\text { No. }\end{array}$ & $\underset{\substack{\text { SALINIIT } \\
\text { S } 0 / 00}}{ }$ & $\begin{array}{l}\text { SEEDING TEMP. } \\
T_{n}{ }^{\circ} \mathrm{C}\end{array}$ & $\begin{array}{c}\text { MIN. TEMP. } \\
T_{\min }{ }^{\circ} \mathrm{C} \\
\end{array}$ & 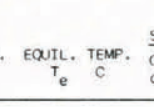 & $\begin{array}{l}\text { Sething } \\
\text { One lume } \\
\text { of ice }\end{array}$ & $\begin{array}{l}\text { Methon } \\
\text { Mary } \\
\text { nuclei i }\end{array}$ & $\begin{array}{l}\text { SUPERCDOU IN } \\
\text { AT SEEDDING } \\
\Delta T_{n}=T^{-T} e_{n}\end{array}$ & & 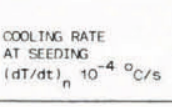 & $\begin{array}{l}\text { TIME of MTN. } \\
\text { TEMP. } \\
t_{\text {min }} \text { sec. }\end{array}$ & $\begin{array}{l}\text { grapac. TIME } \\
\text { tc. } \\
\text { sec. }\end{array}$ & 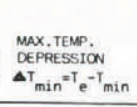 & $\Delta T_{s}=\Delta T_{\min }-\Delta T_{n}$ & 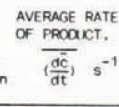 \\
\hline A & $\begin{array}{l}1 \\
2 \\
3 \\
4 \\
5 \\
6 \\
7 \\
8 \\
4\end{array}$ & $\begin{array}{r}47.1 \\
48.7 \\
48.7 \\
49.6 \\
49.6 \\
47.0 \\
47.1 \\
46.3 \\
\\
\end{array}$ & $\begin{array}{l}-2.681 \\
-3.1 .150 \\
-3.50 \\
-3.750 \\
-4.470 \\
-2.770 \\
-3.770 \\
-4.250 \\
-4.650\end{array}$ & $\begin{array}{l}-2.695 \\
-3.1 .155 \\
-3.50 \\
-3.7473 \\
-4.474 \\
-2.802 \\
-3.200 \\
-4.651\end{array}$ & $\begin{array}{l}-2.651 \\
-2.660 \\
-2.675 \\
-2.775 \\
-2.746 \\
-2.640 \\
-2.636 \\
-2.667\end{array}$ & $\begin{array}{l}x \\
x \\
x\end{array}$ & $\begin{array}{l}x \\
x \\
x \\
x \\
x \\
x\end{array}$ & $\begin{array}{l}0.030 \\
0.490 \\
0.915 \\
0.990 \\
1.424 \\
0.130 \\
0.614 \\
1.983 \\
\end{array}$ & Av. & $\begin{array}{l}-5.13 \\
-4.43 \\
-3.37 \\
-3.70 \\
-3.23 \\
-4.12 \\
-4.39 \\
-3.31 \\
-3.90 \\
\end{array}$ & $\begin{array}{r}72 \\
16 \\
0 \\
7 \\
6 \\
6 \\
125 \\
23 \\
3\end{array}$ & $\begin{array}{r}348 \\
80 \\
30 \\
39 \\
24 \\
240 \\
77 \\
72 \\
22\end{array}$ & $\begin{array}{l}0.045 \\
0.505 \\
0.915 \\
0.993 \\
1.948 \\
0.162 \\
0.624 \\
1.994\end{array}$ & $\begin{array}{l}0.015 \\
0.015 \\
0.000 \\
0.003 \\
0.004 \\
0.032 \\
0.010 \\
0.001\end{array}$ & $\begin{array}{l}7.554 \times 10^{-6} \\
8.693 \times 10^{-5} \\
3.182 \times 10^{-4} \\
3.240 \times 10^{-4} \\
8.220 \times 10^{-4} \\
7.897 \times 10^{-6} \\
7.249 \times 10^{-4} \\
1.000 \times 10^{-3}\end{array}$ \\
\hline $\begin{array}{l}\text { B } \\
\text { Series } 1\end{array}$ & $\begin{array}{r}1 \\
2 \\
3 \\
4 \\
5 \\
6 \\
4 \\
\end{array}$ & $\begin{array}{r}23.0 \\
23.5 \\
223.5 \\
23.0 \\
232.0 \\
.22 .6 \\
v .23 .1 \\
. . .\end{array}$ & $\begin{array}{l}-1.200 \\
-1.213 \\
-1.250 \\
-1.650 \\
-2.160 \\
-2.640\end{array}$ & $\begin{array}{l}-1.222 \\
-1.239 \\
-1.2261 \\
-1.61 \\
-2.165 \\
-2.645\end{array}$ & $\begin{array}{l}-1.148 \\
-1.1 .158 \\
-1.158 \\
-1.146 \\
-1.145 \\
-1.45 \\
-1.155\end{array}$ & & $\begin{array}{l}x \\
x \\
x \\
x \\
x \\
x \\
x\end{array}$ & $\begin{array}{l}0.052 \\
0.055 \\
0.052 \\
0.092 \\
1.015 \\
1.485 \\
1.485\end{array}$ & & $\begin{array}{r}-4.96 \\
-5.96 \\
-4.89 \\
-4.56 \\
-4.98 \\
-4.98 \\
-4.95\end{array}$ & $\begin{array}{l}80 \\
93 \\
24 \\
14 \\
9 \\
8\end{array}$ & $\begin{array}{l}426 \\
2291 \\
234 \\
68 \\
38 \\
24\end{array}$ & $\begin{array}{l}0.072 \\
0.071 \\
0.1083 \\
0.511 \\
1.020 \\
1.487\end{array}$ & $\begin{array}{l}0.020 \\
0.026 \\
0.011 \\
0.007 \\
0.005 \\
0.002\end{array}$ & $\begin{array}{l}8.088 \times 10^{-6} \\
1.124 \times 10^{-5} \\
1.093 \times 10^{-5} \\
1.062 \times 10^{-4} \\
3.801 \times 10^{-4} \\
9.960 \times 10^{-4}\end{array}$ \\
\hline Series 2 & $\begin{array}{l}1 \\
2 \\
3 \\
4 \\
5 \\
4\end{array}$ & $\begin{array}{r}11.4 \\
11.4 \\
11.4 \\
11.5 \\
11.5 \\
.11 .45 \\
11.45\end{array}$ & $\begin{array}{l}-0.605 \\
-0.650 \\
-1.050 \\
-1.550 \\
-1.240\end{array}$ & $\begin{array}{l}-0.620 \\
-0.663 \\
-1.056 \\
-1.553 \\
-2.043\end{array}$ & $\begin{array}{l}-0.556 \\
-0.550 \\
-0.546 \\
-0.546 \\
-0.545 \\
-0.548\end{array}$ & & $\begin{array}{l}x \\
x \\
x \\
x \\
x\end{array}$ & $\begin{array}{l}0.049 \\
0.190 \\
0.504 \\
1.005 \\
1.492 \\
\end{array}$ & & $\begin{array}{l}-3.73 \\
-4.04 \\
-4.86 \\
-4.53 \\
-4.54 \\
-4.34 \\
-4.34\end{array}$ & $\begin{array}{c}55 \\
48 \\
10 \\
13 \\
5\end{array}$ & $\begin{aligned} 270 \\
224 \\
51 \\
42 \\
27\end{aligned}$ & $\begin{array}{l}0.064 \\
0.113 \\
0.510 \\
1.000 \\
1.495\end{array}$ & $\begin{array}{l}0.015 \\
0.013 \\
0.006 \\
0.003 \\
0.003\end{array}$ & $\begin{array}{l}7.739 \times 10^{-6} \\
.1 .68 \times 10^{-5} \\
1.46 \times 10 \times 10^{-4} \\
3.832 \times 10^{-4} \\
7.440 \times 10^{-4}\end{array}$ \\
\hline Series 3 & $\begin{array}{r}1 \\
2 \\
3 \\
3 \\
4 \\
5 \\
6 \\
7 \\
8 \\
9 \\
10 \\
11 \\
12\end{array}$ & $\begin{array}{l}0 \\
0 \\
0 \\
0 \\
0 \\
0 \\
0 \\
0 \\
0\end{array}$ & $\begin{array}{l}-0.029 \\
-0.0262 \\
-0.0 .100 \\
-0.500 \\
-1.000 \\
-1.5000 \\
-0.028 \\
-0.058 \\
-0.058 \\
-0.104 \\
-0.500 \\
-1.000 \\
-1.520\end{array}$ & $\begin{array}{l}-0.042 \\
-0.066 \\
-0.108 \\
-0.506 \\
-1.003 \\
-1.503 \\
-0.064 \\
-0.129 \\
-0.118 \\
-0.505 \\
-1.000 \\
-1.525\end{array}$ & $\begin{array}{c}0.000 \\
0.000 \\
0.000 \\
0.000 \\
0.000-0.002 \\
-0.001-0.000 \\
0.000 \\
0.000 \\
-0.001-0.000 \\
0.0000 \\
-0.000 \\
0.000 \\
0.0000\end{array}$ & $\begin{array}{l}x \\
x \\
x \\
x \\
x \\
x \\
x\end{array}$ & $\begin{array}{l}x \\
x \\
x \\
x \\
x \\
x \\
x\end{array}$ & $\begin{array}{l}0.029 \\
0.062 \\
0.100 \\
0.500 \\
1.000 \\
1.500 \\
0.028 \\
0.058 \\
0.104 \\
0.500 \\
1.000 \\
1.520\end{array}$ & Av. & $\begin{array}{l}-5.68 \\
-5.85 \\
-6.02 \\
-4.711 \\
-5.94 \\
-4.73 \\
-6.73 \\
-5.70 \\
-5.26 \\
-6.35 \\
-5.35 \\
-4.47 \\
-4.47 \\
-5.56\end{array}$ & $\begin{array}{c}35 \\
11 \\
17 \\
11 \\
8 \\
11 \\
68 \\
149 \\
45 \\
45 \\
15 \\
1 \\
3\end{array}$ & $\begin{array}{l}115 \\
52 \\
103 \\
103 \\
23 \\
25 \\
24 \\
243 \\
774 \\
126 \\
36.5 \\
16 \\
16.5 *\end{array}$ & $\begin{array}{l}0.042 \\
0.066 \\
0.108 \\
0.506 \\
1.003 \\
1.503 \\
0.064 \\
0.129 \\
0.118 \\
0.505 \\
1.000 \\
1.525\end{array}$ & $\begin{array}{l}0.013 \\
0.004 \\
0.008 \\
0.006 \\
0.003 \\
0.003 \\
0.036 \\
0.061 \\
0.014 \\
0.005 \\
0.000 \\
0.005\end{array}$ & $\begin{array}{l}1.301 \times 10^{-5} \\
2.542 \times 10^{-5} \\
2.165 \times 10^{-5} \\
2.022 \times 10^{-4} \\
7.597 \times 10^{-4} \\
1.214 \times 10^{-3} \\
1.249 \times 10^{-5} \\
1.894 \times 10^{-5} \\
2.296 \times 10^{-5} \\
2.722 \times 10^{-4} \\
7.564 \times 10^{-4} \\
1.276 \times 10^{-3}\end{array}$ \\
\hline c & $\begin{array}{l}1 \\
2 \\
3 \\
4 \\
5 \\
6 \\
7 \\
8 \\
9\end{array}$ & 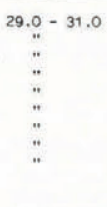 & $\begin{array}{ll}0 & -1.728 \\
-1.800 \\
-1.900 \\
-2.000 \\
-2.100 \\
-2.200 \\
-2.300 \\
-2.400 \\
-2.400 \\
-2.500\end{array}$ & $\begin{array}{l}-1.764 \\
-1.1812 \\
-1.9110 \\
-2.000 \\
-2.102 \\
-2.201 \\
-2.302 \\
-2.002 \\
-2.002 \\
-2.501\end{array}$ & $\begin{array}{r}-1.728 \\
-1.7708 \\
-1.732 \\
-1.746 \\
-1.763 \\
-1.7777 \\
-1.748 \\
-1.7763 \\
-1.758 \\
-1.758\end{array}$ & & $\begin{array}{l}x \\
x \\
x \\
x \\
x \\
x \\
x \\
x \\
x \\
x\end{array}$ & $\begin{array}{l}0.000 \\
0.092 \\
0.168 \\
0.254 \\
0.337 \\
0.423 \\
0.552 \\
0.637 \\
0.742\end{array}$ & & $\begin{array}{l}-2.68 \\
-2.50 \\
-2.77 \\
-2.71 \\
-2.63 \\
-2.63 \\
-2.63 \\
-2.61 \\
-2.61 \\
-2.81 \\
-2.63\end{array}$ & $\begin{array}{r}298.00 \\
67.00 \\
45.60 \\
23.70 \\
8.20 \\
6.00 \\
6.40 \\
8.44 \\
3.08\end{array}$ & $\begin{array}{l}547.00 \\
341.00 \\
222.60 \\
152.00 \\
103.30 \\
75.20 \\
67.60 \\
54.84 \\
51.00\end{array}$ & $\begin{array}{l}0.036 \\
0.104 \\
0.178 \\
0.262 \\
0.339 \\
0.424 \\
0.554 \\
0.659 \\
0.743\end{array}$ & $\begin{array}{l}0.036 \\
0.012 \\
0.010 \\
0.008 \\
0.002 \\
0.002 \\
0.001 \\
0.002 \\
0.002 \\
0.001\end{array}$ & 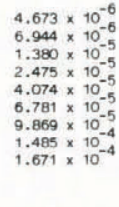 \\
\hline
\end{tabular}

Note: 1. Time is zero at seeding point. 2. The asterisk symbol indicates time measured from time zero other than the seeding point.

consisted of five experiments for which the salinity of the water was about $11.5 \%$, For series 3, distilled water was used for a total of 12 experiments, giving a zero salinity to the experimental water. The same experimental set-up and procedure that were employed in group A experiments were also used in this group of experiments. The artificial sea-water was also prepared from "Forty Fathoms" solution in distilled water. For the experiments in series 1 and 2 , the supercooled water was seeded with fresh-water ice seeds scraped from a piece of ice with a saw blade. For the distilled water experiments in series 3 , the supercooled water was seeded with scraped fresh-water ice seeds for six experiments and seeded with one pea-sized lump of ice for the other six experiments. The experimental results were all chart-recorded. The parameters of the experiments are shown in Table I.

\section{Group C experiments}

Genuine Atlantic sea-water (from Halifax harbour) was used in this group of experiments. The salinity of the water for individual experiments was not recorded, but was within the range $29-31 \%$. A total of nine experiments were conducted in a cold room in a Plexiglass, race-course-shaped flume. The rectangular cross-section of the flume measured $15 \mathrm{~cm}$ wide $\times 13 \mathrm{~cm}$ high with water filled to $2 \mathrm{~cm}$ from the top. The overall dimensions of the flume were $130 \mathrm{~cm}$ long $x$ $65 \mathrm{~cm}$ wide. The recirculating flume was enclosed in a warm air jacket except its upper surface, which was exposed to the air. The temperature of the warm air jacket was maintained at about $5^{\circ} \mathrm{C}$ for the experiments while the surface was cooled by a wind of about $0.5 \mathrm{~m} / \mathrm{s}$ set up by a fan. A stirrer was inserted into the flume at one end and produced a current of about $15 \mathrm{~cm} / \mathrm{s}$ in the flume. The flow Reynolds number corresponding to this flow velocity and a temperature of $-1.75^{\circ} \mathrm{C}$, which was approximately the freezing temperature of the sea-water, was $8.54 \times 10^{3}$. The cold room was set at $-10^{\circ} \mathrm{C}$ but its actual temperature fluctuated between $-9.5^{\circ} \mathrm{C}$ and $-12.5^{\circ} \mathrm{C}$. The cooling rate of the water was measured to vary within the narrow range of $2.50 \times 10^{-4}$ to $2.83 \times 10^{-4} \mathrm{deg} / \mathrm{s}$. The production of frazil in the supercooled water was initiated with fresh-water ice seeds. The temperature of the water was monitored with a precision thermometer with a resolution and repeatability of $0.001 \mathrm{deg}$. The experimental results were recorded on a high-precision chart recorder. The parameters of the experiments are shown in Table I. A more detailed description of the experiments has been given by Tsang (1983).

\section{ANALYSIS OF EXPERIMENTAL DATA AND EXPERIMENTAL RESULTS}

\section{Average rate of frazil production}

It was mentioned in the Introduction that Hanley and Tsang studied the average rate of frazil production in the initial period and found that it increased by almost three orders of magnitude as the supercooling increased from zero to $2.0 \mathrm{deg}$. Their average rate of frazil production was defined as

$$
\left[\overline{\frac{d \bar{c}_{i}}{d t}}\right]=\frac{\bar{c}_{i c}-\bar{c}_{i \min }}{t_{c}-t_{\min }}
$$

where the subscript $c$ indicates the moment when $90 \%$ of the maximum temperature depression had been recovered and the subscript min indicates the instant of minimum temperature. The concentration of frazil as a function of time and water temperature is given by Equation (4). Writing Equation (4) for the above two instants and then subtracting the two resulting equations
yields 


$$
\begin{aligned}
\bar{c}_{i c}-\bar{c}_{i \min }= & \frac{c}{H_{L}}\left[-\left[\frac{d \bar{T}}{d t}\right]_{n}\left(t_{c}-t_{\min }\right)+\right. \\
& \left.+\left(T_{c}-T_{\min }\right)\right]
\end{aligned}
$$

By writing $0.9 \Delta \mathrm{T}_{\min }$ for $\left(\mathrm{T}_{\mathrm{c}}-\mathrm{T}_{\min }\right)$ and $\mathrm{rc}_{\mathrm{o}}$ for $\mathrm{c}$, where $c_{0}$ is the specific heat of fresh-water and $r$ is a salinity-dependent coefficient, the above equation may be rearranged to

$$
\begin{gathered}
{\left[\overline{\left.\frac{d \bar{c}_{i}}{d t}\right]=\frac{\bar{c}_{i c}-\bar{c}_{i \min }}{t_{c}-t_{\min }}}=r \frac{c_{0}}{H_{L}}\left[-\left[\frac{d \bar{T}}{d t}\right]_{n}+\right.\right.} \\
\left.+\frac{0 / 9 \Delta T_{\min }}{t_{c}-t_{\min }}\right] .
\end{gathered}
$$

For the above equation, the ratio $\mathrm{c}_{0} / \mathrm{H}_{\mathrm{L}}$ is $1 / 80$ if the Celsius temperature scale is used, the values of $r$ for salinities $48.1,30.0,23.1,11.5$, and 0.00 parts per mille are $0.916,0.939,0.947,0.966$, and 1.000 respectively (see table 129, Dorsey (1940), p. 273) and the other parameters appearing on the right-hand side of Equation (16) are tabulated in Table $I$; the average rate of frazil production $\overline{\mathrm{d} \overline{\mathrm{c}} / \mathrm{d}} \mathrm{i}$ can therefore be calculated for all the experiments, as shown also in Table I.

According to Table $I$, the average rate of frazil production $\overline{\mathrm{d} \overline{\mathrm{c}}_{\mathrm{i}} / \mathrm{dt}}$ was plotted against supercooling at seeding as shown in Figure 2. It is seen from Figure 2 that all the data points of the saline water experiments, regardless of the salinity of the water, come together into a single functional relationship. The experimental data points for natural sea-water also intermingle with the data points for the experiments on artificial sea-water. This indicates that for predicting the average rate of frazil production, "Forty Fathoms" solution in water may be used as the sea-water in laboratory model experiments. The functional relationship defined by the distilled-water experimental data is distinctly different from the saline frazil relationship. By comparing the two relationships, one sees that under the same parametric conditions, fresh-water frazil will be produced at a much greater rate than saline-water frazil. Since the transition from fresh water to saline water is gradual, one may ask how the relationship between production rate and supercooling changes from the fresh-water one to the saline-water one as the salinity of

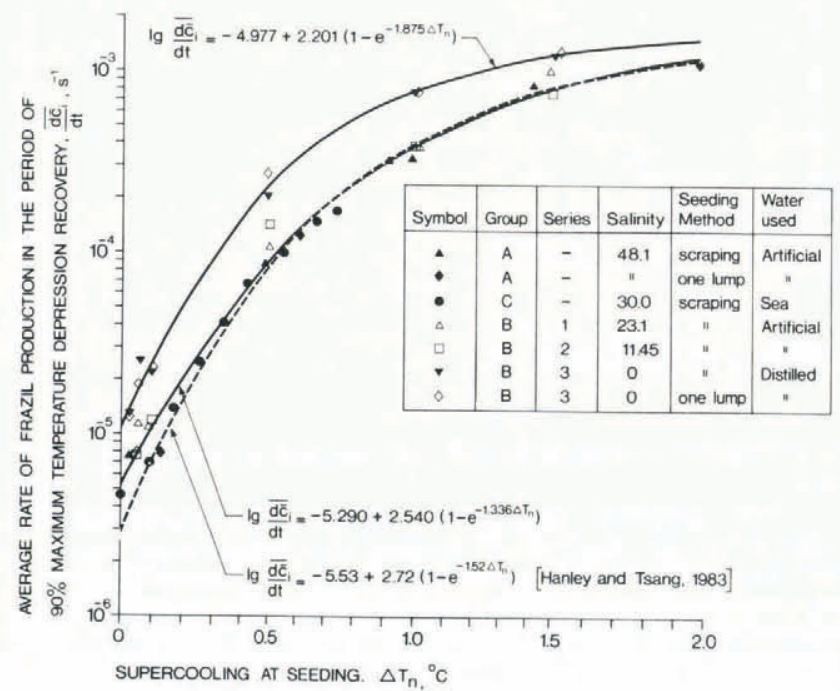

Fig. 2. Average rate of frazil production at different initial supercoolings. the water is increased from zero to $11.45 \%$ Apparently more experiments are needed for this range of salinity. It is interesting to note that for the cooling-rate range of the present experiments, the average frazil production rate does not seem to be affected by the rate of cooling or the rate of heat loss of the water.

Hanley and Tsang proposed the following equation for the relationship between initial supercooling at seeding and the average rate of frazil production based on their experiments on saline water of $48.1 \%$ salinity:

$$
\log \frac{\overline{\mathrm{d} \bar{c}_{\mathrm{i}}}}{\mathrm{dt}}=-5.53+2.72\left(1-\mathrm{e}^{-1.52 \Delta \mathrm{T}_{\mathrm{n}}}\right)
$$

The curve given by the above equation is shown in Figure 2 as a dotted line. It is seen from Figure 2 that while the curve fits the saline-water experimental data well with initial supercoolings greater than $0.5 \mathrm{deg}$ for initial supercoolings less than this value, the equation gives too low a rate of frazil production. A slight modification of the above equation to

$$
\log \frac{\overline{\mathrm{d} \overline{\mathrm{c}}_{\mathrm{i}}}}{\mathrm{dt}}=-5.290+2.540\left(1-\mathrm{e}^{-1.336 \Delta \mathrm{T}_{\mathrm{n}}}\right)
$$

gives a much better fit as shown in Figure 2. This equation is obtained by fitting the data points to the curve using the method of least squares. The coefficient of determination* of the above fit is $R^{2}=0.988$ and the estimate of standard deviation is $\sigma=0.088\left(\mathrm{~S}^{-1}\right)$. It should be noted that in the empirical fitting here and elsewhere in the paper, the three decimal places are assigned in the computer program and not intended as a measure of precision.

For the distilled water experiments, again using the method of least squares, the fitting curve is found to be

$$
\log \frac{\overline{\mathrm{d} \overline{\mathrm{c}_{\mathrm{i}}}}}{\mathrm{dt}}=-4.977+2.201\left(1-\mathrm{e}^{-1.875 \Delta \mathrm{T}_{\mathrm{n}}}\right) .
$$

The coefficient of determination and the estimate of standard deviation are, respectively, 0.995 and $0.065\left(\mathrm{~S}^{-1}\right)$. It will be reasonable to expect that for saline water with a salinity in the range of 0 to $11.4 \% \%$, the average rate of frazil production would be given by relationships of the same functional form as the last two equations, but with the coefficients falling in the range between those shown in Equations (18) and (19).

Normalized concentration as a function of normalized time

The normalized concentration of frazil, as given by Equation (9), was plotted against the normalized time for the different groups and series of experiments as shown in Figure $3 a$ to $e$ in order of decreasing salinity.

* For a set of $\mathrm{n}$ data points specified by $\left(\mathrm{x}_{\mathrm{i}}, \mathrm{y}_{\mathrm{i}}\right)$ where $\mathrm{i}$ $=1$ to $\mathrm{n}$, if a functional relationship $\mathrm{y}=\mathrm{f}(\mathrm{x})$ is used to fit the points, then the coefficient of determination and the estimate of standard deviation of the fit are defined, respectively, as

$$
\begin{aligned}
& R^{2}=\frac{\left.\left.\sum\left(y_{i}-\bar{y}\right)^{2}-\sum\left(y_{i}-f\right) x_{i}\right)\right)^{2}}{\sum\left(y_{i}-\bar{y}\right)^{2}} \\
& \text { and } \\
& \sigma=\sqrt{\frac{1}{n-m} \sum\left(y_{i}-f\left(x_{i}\right)\right)^{2}}
\end{aligned}
$$

where $\bar{y}$ is the mean of the $y_{i}$ and $m$ is the number of parameters of the fitting function. 

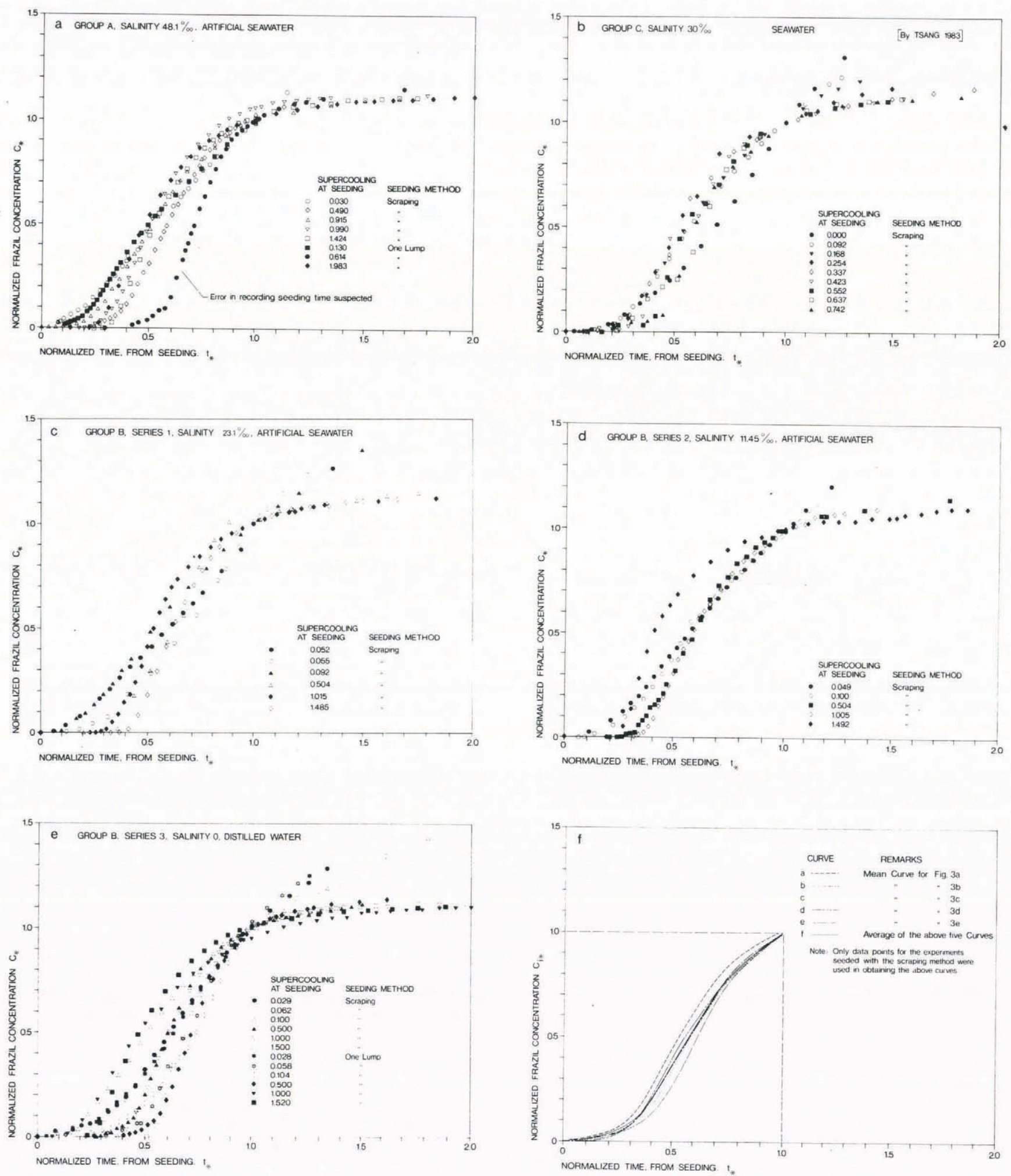

Fig. 3. Normalized concentration as a function of normalized time.

It is seen from these plots that for each batch of experiments the data points congregate to give a reasonably well-defined functional relationship. There is a certain degree of scattering of the data points. A close examination of the scattering, however, reveals that it is not systematically dependent $\mathrm{or}_{\mathrm{i}}$ the initial supercooling of the water. A data point for a higher initial supercooling can be either above or below a data point for a lower initial supercooling. The scatter of the data points, therefore, is considered to be caused by the experimental uncertainty and the method of handling the data.

The greatest causes of experimental uncertainty came from the method of seeding the supercooled water and from the difficulty of maintaining a constant level of turbulence. For the experiments, the supercooled water was either seeded with ice particles by scraping a slab of ice three times with a saw blade or seeded with a pea-sized lump of ice dropped into the water when the seeding signal was given. Since the seeding procedure 

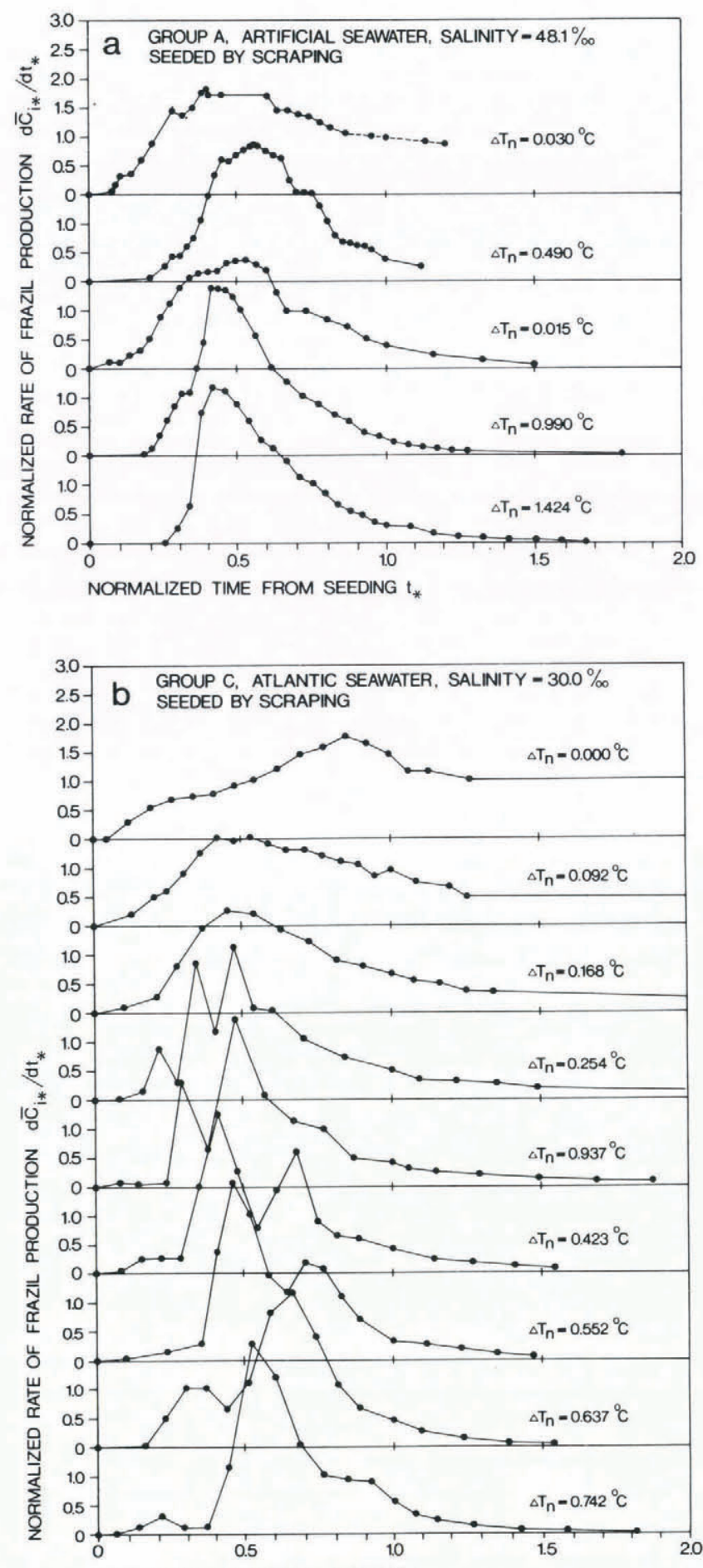

NORMALIZED TIME FROM SEEDING $t_{*}$

Fig. 4. Normalized rate of frazil production as a function of normalized time.

was manual, it was difficult to control the number of ice seeds, the duration of seeding, the place of ice-seed deposition and the time lag between giving the signal and the commencement of seeding action. As for the maintenance of turbulence level, except for Group C experiments, there was no quantitative criterion to ensure that the turbulence level was the same. Observations during the experiments showed that greater experimental uncertainty may be expected if the supercooled water is seeded with one lump of ice.

The uncertainty produced by the method of data handling came mainly from the fact that the

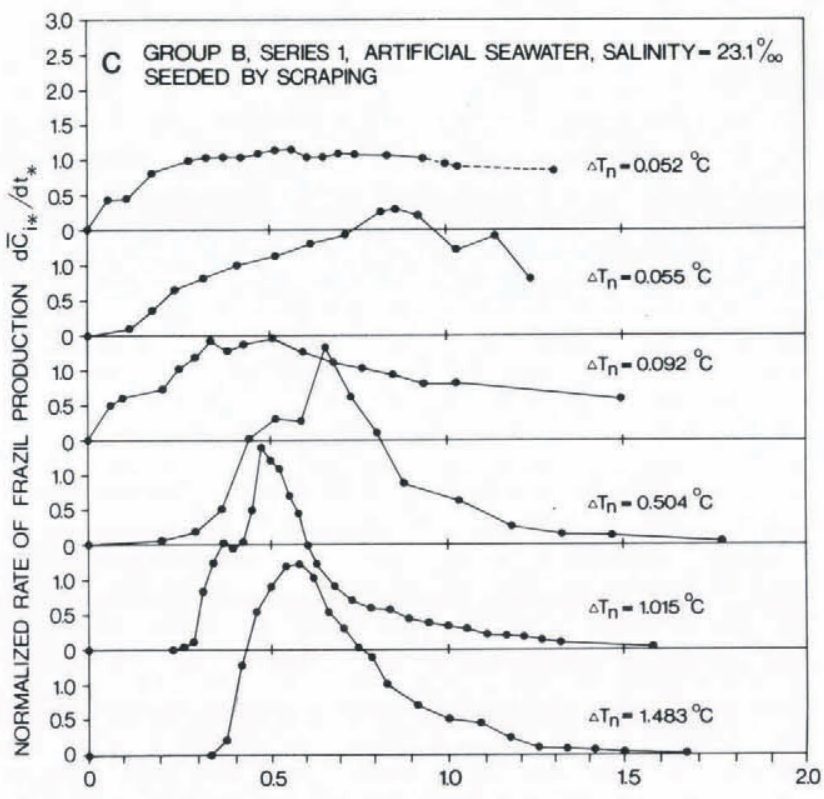

NORMALIZED TIME FROM SEEDING $\mathrm{t}$
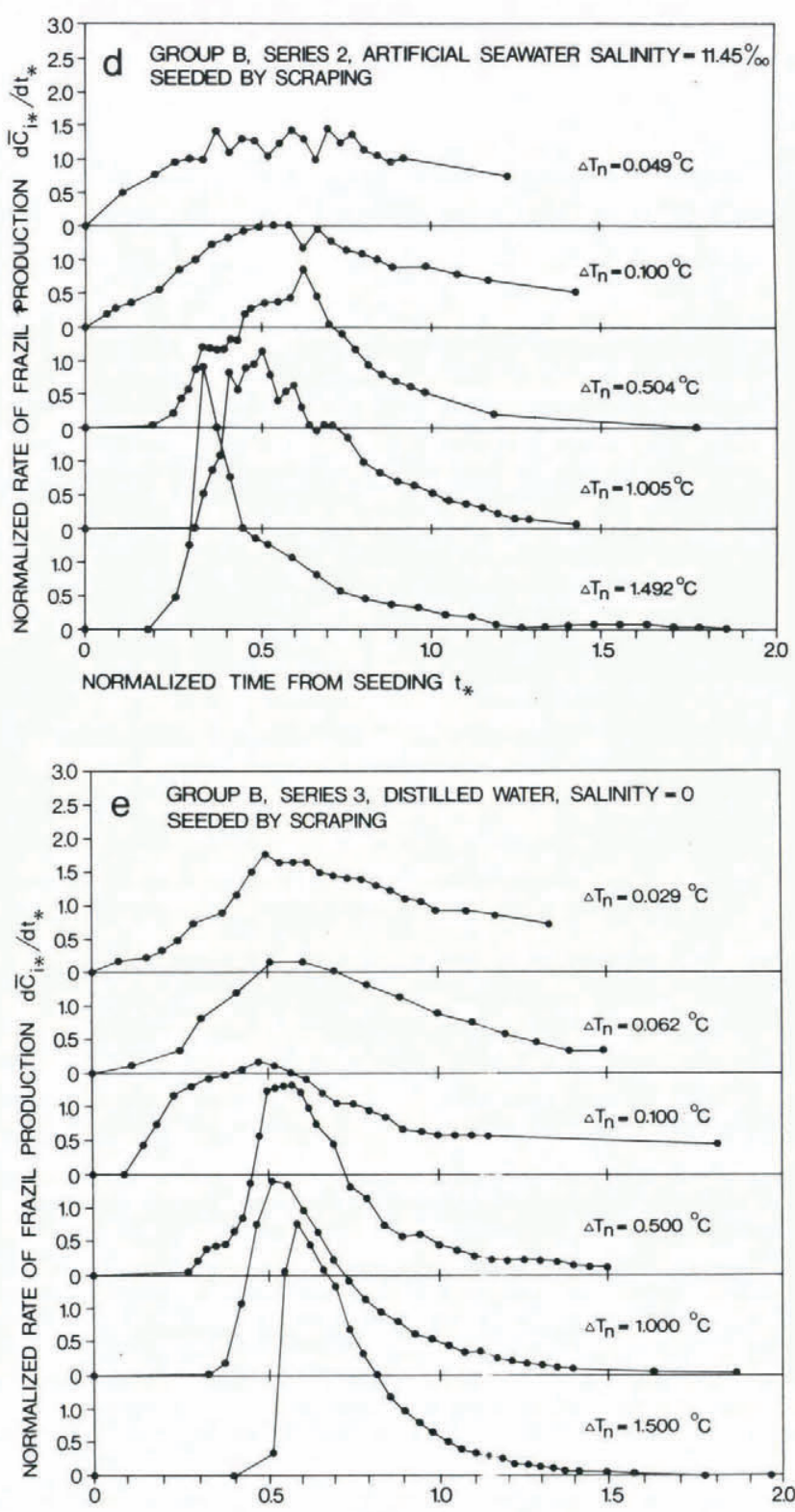

NORMALIZED TIME FROM SEEDING $t_{*}$ 
experimental results were first recorded on a strip chart and then the numerical values of temperature and time were read from the chart. When reading from the chart, a certain degree of subjective judgement is always involved and that is ultimately reflected in the scatter of the data. The rounding of $f$ of digits also adds to the uncertainty. The degree of uncertainty caused by this method of data handling can be seen from the departure of the data points at $t_{*}=1$, from $c_{*}=1$. According to the definition of normalization, theoretically, at $t *=1$, c* should always be equal to unity. However, the plots, especially Figure $3 \mathrm{a}$ and $\mathrm{e}$, show that this is not always the case. One may consider using error bars or other statistical indicators to show the scatter of the data points in Figure $3 \mathrm{a}$ to e. This, however, was ruled out because the number of experiments conducted was small and the experimental method left much room for future refinement. To give too much statistical interpretation to the experimental data at this point would be premature and could cause misunderstandings.

By dividing the data points into sections of equal t* increment of $\Delta t *=0.1$, the centre of mass for the points in each section can be obtained and a curve can be drawn to fit all the centres of mass so obtained. Figure $3 \mathrm{f}$ shows the five curves fitted to Figure $3 \mathrm{a}$ to e. It should be noted that in obtaining these curves, only the data points of the experiments seeded by the scraping method were used. The reason for doing so was to reduce the effect of experimental uncertainty noted earlier. It is seen from Figure $3 f$ that these five curves, which are shown as dotted lines, are fairly close to each other, indicating that, regardless of the salinity of the water and whether the water is naturally obtained or artificially prepared from "Forty Fathoms", within a certain range of design error, the concentration of frazil can be predicted from a unique functional relationship. In Figure $3 \mathrm{f}$, this relationship is shown by the solid line which is the average of the five dotted line curves.

The curves in Figure $3 \mathrm{f}$ are plotted for the range $t_{*}=0$ to 1.0 only. Beyond $t_{*}=1.0$, single curves for the different groups and series of experiments do not exist because the asymtoptic slopes of the $\mathrm{c} *=\mathrm{t} *$ curves of the individual experiments would be all different, as determined by their rates of heat loss to the atmosphere. The practical significance of Figure $3 \mathrm{f}$ is that for the range of $t_{*}=0$ to 1.0 or a little beyond, which is important for engineering, a usable functional relationship now exists which permits the prediction of frazil concentration at any given time.

Normalized rate of frazil production as function of normalized time

From the experimental record and according to Equation (12), the normalized rate of frazil production was plotted against the normalized time for the experiments as shown in Figure 4 where plots a to $e$ are in order of decreasing salinity. Again, only the experiments seeded by the scraping method were used in plotting in order to reduce the experimental uncertainty. The following interesting points can be noted from comparing the plots:

1. Although all the curves of rate of production are bell-shaped, they can be either single moded or bimodal. For some curves, although they seem to be multimodal, the peaks are not dominant and were probably produced by the noise level of the instrument or the method of data handling and analysis. For instance, for the curve for a supercooling of $0.049 \mathrm{deg}$ in Figure $4 \mathrm{~d}$, the jagged shape of the curve could easily be smoothed out by reading the temperature a few thousandths of a degree up or down, a thing quite easily justified seeing that the thickness of the line on the strip chart can cover several thousandths of a degree.

2. For the experiment performed with distilled water, it is seen from Figure 4e that the production-rate curves are distinctly single peaked. The reason for such a curve shape may be because only one kind of frazil crystal is produced in the water. Tsang (1983) in his photographic study of frazil showed that when distilled water was used, the frazil crystals produced in the water were all discoids. The single-peaked, bell-shaped curve therefore may be the typical production curve of discoid frazil crystals.

3. For the sea-water experiments, Figure $4 \mathrm{~b}$ clearly shows that the production curves for supercoolings greater than $0.168 \mathrm{deg}$ were bimodal. For supercooling equal to $0.254 \mathrm{deg}$, although the curve shows a weak third peak, this third peak is judged to be not systematic but caused by experimental fluctuation. The double-peaked production curve may be again explained by the types of frazil crystals produced. Tsang (1983) showed photographically that for sea-water, two types of frazil crystals may be produced, the Christmas-star-shaped ones and the three-dimensional thorn-ball shaped ones. If the production curve of each crystal type is bell-shaped with a single peak, then the bimodal total production curves can be easily explained. If one visualized that the magnitude and location of the peaks are functions of supercooling, then the superposition of two single-peaked production curves at different relative positions and strengths can quite easily produce all the curves shown in Figure $4 \mathrm{~b}$. The gradual dominance of one peak and diminishing of the other can be interpreted as the growing dominance of one kind of frazil crystal over the other. Careful studies of the crystallographic growth of frazil crystals should shed some light on the theory proposed above.

4. For the experiments conducted with artifical sea-water, it is seen from Figure $4 a, c$, and $d$ that although two clear peaks are not seen from the curves, there seems to be a suppressed second peak for curves with supercoolings in the approximate range of 0.5 to $1.0 \mathrm{deg}$. There may be two reasons for the different frazil production curves for natural and artificial sea-waters. The first is that different types of frazil crystals may be produced in the two different waters and the second is that different instruments were used in the different groups of experiments. Because Hanley and Tsang (1984) could not study the individual crystals in their experiments with artificial sea-water, the crystallographic structure of frazil formed from artificial sea-water is not clearly known. The idea that the curves are different because different types of frazil crystals are produced in natural and artificial sea-water can only be a conjecture waiting to be clarified in the future. With regard to the instrument used, it may be noted that during the experiments of Group $A$ and Group $B$, a chart recorder with a slow response was used. This slow recorder might not have been able to record the fast changes in production rate shown by the curves in Figure 4b. A high-quality chart recorder with a fast response was used for experiments with natural sea-water which produced Figure $4 \mathrm{~b}$.

5. Regardless of the salinity of the water and whether the sea-water was artificial or natural, Figure 4 shows that as supercooling increased, the peak value of

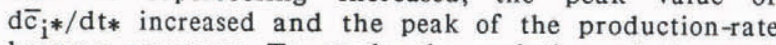
became narrower. To study the variation of the peak production rate with supercooling, the maximum value of $\mathrm{dc}_{\mathrm{i}^{*}} / \mathrm{dt}$ * was plotted against the supercooling at the time of seeding, for all the experiments that were seeded by the scraping method, as shown in Figure 5 . Although the scatter of the points in Figure 5 is such that it does not seem possible to establish a reliable functional relationship from the data, there is an unmistakable trend showing that the normalized maximum rate of frazil production increases with supercooling (the straight line in the figure is intended only to aid the eye in perceiving this trend) and that the salinity of the water and the nature of the water (namely whether it is natural or artificial) do not seem to affect the above trend in a systematic way. 


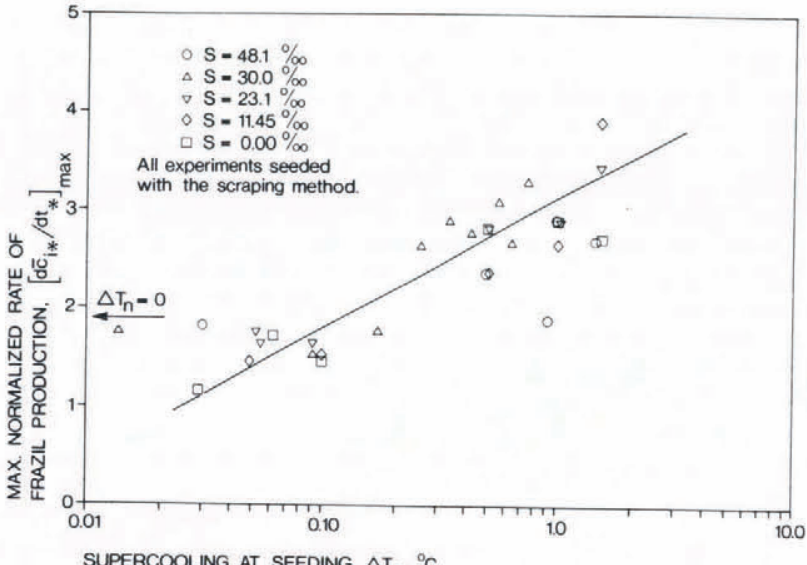

Fig. 5. Change of maximum rate of frazil production with initial supercooling.

Variation of characteristic parameters as functions of supercooling at seeding

To convert the concentration of frazil in water and the rate of frazil production as functions of time from the normalized form to the dimensional form, one needs to know the characteristic time $t_{c}$ and the characteristic concentration of frazil $\bar{c}_{\text {ic }}$ (see Equation (8)). From Equations (7) and (11), one also sees that if the cooling rate of the water at seeding $(\mathrm{dT} / \mathrm{dt})_{n}$, the characteristic time $t_{c}$, and the maximum temperature depression $\Delta T_{\text {min }}$ for supercooling at seeding $\Delta T_{n}$ are known, then the characteristic concentration $\overline{\mathrm{c}}_{\mathrm{ic}}$ can be readily calculated. Tsang (1983) showed from his experiments on sea-water that for a given rate of cooling of the water at seeding $(\mathrm{dT} / \mathrm{dt})_{\mathrm{n}}$ and a given salinity, $\Delta \mathrm{T}_{\min }$ and $\mathrm{t}_{\mathrm{c}}$ are welldefined functions of $\Delta \mathrm{T}_{\mathrm{n}}$ alone. It follows from Equations (7) and (11) that the characteristic concentration $\bar{c}_{i c}$ would also be a well-defined function of $\Delta T_{n}$. In this section the $\Delta T_{\min }$ versus $\Delta T_{n}, t_{c}$ versus $\Delta T_{n}$, and $\bar{c}_{i c}$ versus $\Delta T_{n}$ relationships for water of different salinities and different rates of cooling will be studied. It is hoped that from systematically studying these relationships, the effect of salinity and cooling rate on them may be found.

Figure 6 is a plot of $\Delta T_{\min }$ versus $\Delta \mathrm{T}_{\mathrm{n}}$ for all the experiments. Because the minimum temperature of the temperature-time curves was not sensitive to the seeding method (although the shape of the curve near the minimum did depend on the method of seeding), the

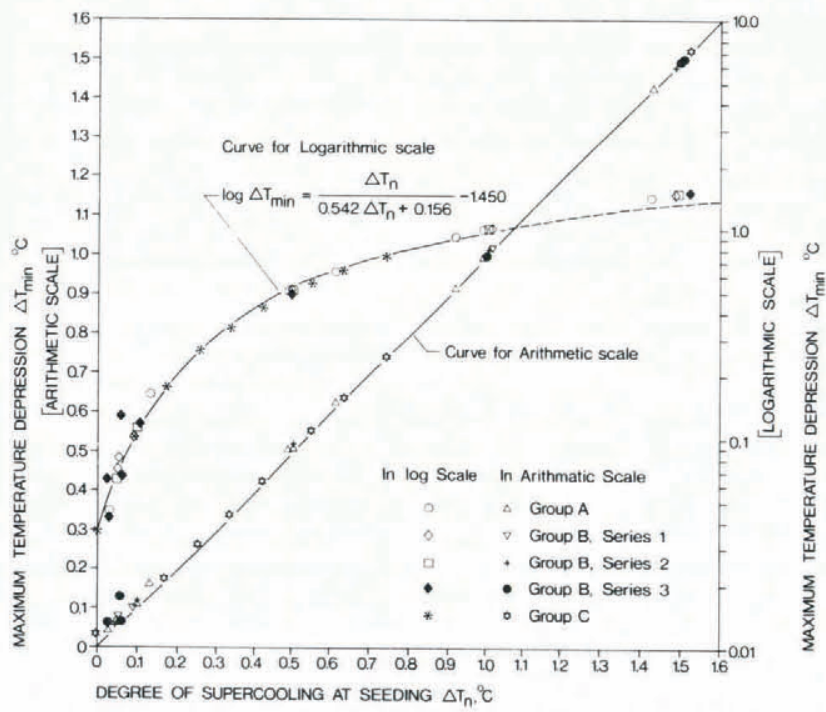

Fig. 6. Maximum temperature depression as a function of initial supercooling. experiments for which the supercooled water was seeded with one lump of ice were also included in the plot. For easy recognition of functional trend, the plot was plotted both with an arithmetic scale and with a semi-logarithmic scale. It is seen from Figure 6 that the relationship between $\Delta \mathrm{T}_{\mathrm{min}}$ and $\Delta \mathrm{T}_{\mathrm{n}}$ is well defined and is not affected by the salinity of the water nor by the rate of cooling of the water in the present experimental range. The data points plotted using an arithmetic scale at large initial supercoolings $\left(\Delta \mathrm{T}_{\mathrm{n}}>0.75 \mathrm{deg}\right)$ fall along the $45^{\circ}$ line, indicating that in this range $\Delta \mathrm{T}_{\text {min }}$ and $\Delta \mathrm{T}_{\mathrm{n}}$ are approximately equal. Measurement of water temperatures in natural rivers, however, have shown that the beginning of frazil production seldom occurred at a supercooling greater than $0.10 \mathrm{deg}$. Thus the range of small supercooling is of much greater practical interest. In the range of small supercooling, a recognizable function trend can be seen in the semi-logarithmic plot, in which the points have been fitted, using the method of least squares, with the equation

$$
\log \Delta \mathrm{T}_{\min }=\frac{\Delta \mathrm{T}_{\mathrm{n}}}{0.542 \Delta \mathrm{T}_{\mathrm{n}}+0.156}-1.450
$$

The coefficient of determination of the above $f$ it is $R^{2}$ $=0.984$ and the estimate of standard deviation is 0.478 (S). To obtain the above equation, only the data points for $\Delta \mathrm{T}_{\mathrm{n}}<1.0 \mathrm{deg}$ were used because for $\Delta \mathrm{T}_{\mathrm{n}}>$ 1.0 deg the points should fall on the line $\Delta T_{\min }=\Delta T_{n}$ The determination of the upper limit of $\Delta T_{n}$ for Equation (20) is somewhat arbitrary. From Figure 6 it is clear that the upper limit could be taken anywhere from 0.7 to 1.0 deg. In Figure 6 the part of the fitted curve for $\Delta \mathrm{T}_{\mathrm{n}}>1.0 \mathrm{deg}$ is shown by a dashed line to emphasize the range of validity of Equation (20). It should be added that although the initial supercooling of a frazil-producing river has been found to be mostly less than $0.10 \mathrm{deg}$, for Arctic waters, a higher initial supercooling may be expected because the air-borne ice particles that cause primary nucleation in the supercooled water are of ten in short supply in the dry Arctic air.

To study the characteristic time $t_{c}$, it was plotted against the initial supercooling $\Delta \mathrm{T}_{\mathrm{n}}$ for all the experiments seeded using the scraping method as shown in Figure 7. To facilitate visual detection of the

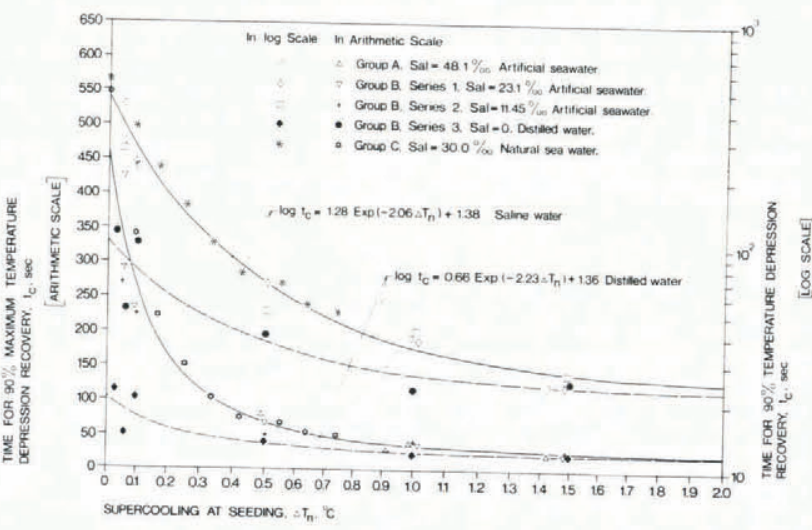

Fig. 7. Relationship between characteristic time and initial supercooling.

functional trend, plotting is again both using an arithmetic scale and a semi-logarithmic scale. It is seen from Figure 7 that in either plot the $t_{c}-\Delta T_{n}$ relationship for the saline water experiments is well defined and is not affected by the salinity of the water in the salinity range of the present experiments of $11.45 \%$ to $48.1 \%$. Although the arithmetic plot suggests an 
exponential suggests an exponential decay type of function, the semi-logarithmic plot shows that a further stage of the same sort of relationship is needed. Based on the data points plotted in the semi-logarithmic scale, the following equation my be fitted to the data points of the saline-water experiments using the method of least squares:

$$
\log t_{c}=1.28 e^{-2.06 \Delta T_{n}}+1.38
$$

The coefficient of determination of the fit is 0.976 and the estimate of standard deviation is 0.071 (S). In Figure 7 , the above equation is plotted both in the semi-logarithmic scale and in the arithmetic scale. It is seen from Figure 7 that visually both curves fit the data points well.

Only a limited number of data points were obtained from the distilled-water experiments. These data points, however, do show a different functional relationship between $t_{c}$ and $\Delta T_{n}$ from that of saline-water experiments. The equation which best fits the data points in the semi-logarithmic plot using the least-squares method is found to be

$$
\log t_{c}=0.66 e^{-2.23 \Delta T_{n}}+1.36
$$

The coefficient of determination of the above fit is 0.829 and the estimate of standard deviation is 0.159 (S). The small number of data points is a factor in the poorer fit. The above equation is also plorted in Figure 7 both in the semi-logarithmic plot and in the arithmetic one.

Obviously the $t_{c}-\Delta T_{n}$ relationships would change from Equation (21) to Equation (22) as the salinity of the water changes from $11.45 \%$ oo to zero. How this change takes place will be an interesting scientific question which can only be answered by further experiments.

The characteristic concentration of frazil in water $\bar{c}_{i c}$ has been calculated according to Equation (7) and has been plotted against the initial supercooling $\Delta \mathrm{T}_{\mathrm{n}}$ in Figure 8. It is seen from Figure 8 that the relationship between $\bar{c}_{\mathrm{ic}}$ and $\Delta \mathrm{T}_{\mathrm{n}}$ is well defined and as a whole can be approximated by the following equation, which was obtained by fitting the equation to the data points using the method of least squares:

$$
\overline{\mathrm{c}}_{\mathrm{ic}}=\left(0.92 \Delta \mathrm{T}_{\mathrm{n}}^{1.187}+0.14\right) \times 10^{-2} \text {. }
$$

The coefficient of determination and the estimate of standard deviation of the above fit are, respectively, 0.989 and $0.053(\%)$. The effect of the salinity of the water and the cooling rate of the water on the $\bar{c}_{i c}-\Delta T_{n}$

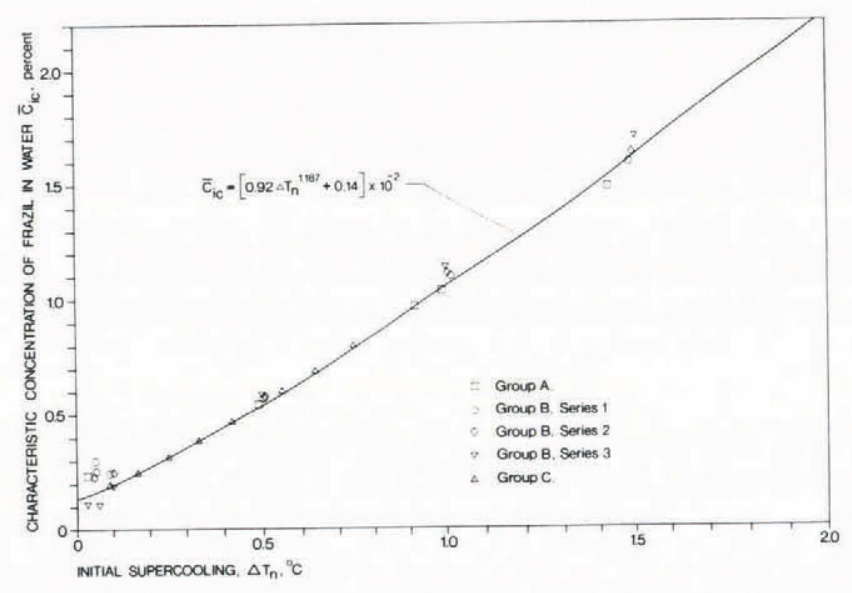

Fig. 8. Characteristic concentration as a function of initial supercooling. relationship, as can be seen from Figure 8 , is insignificant, at least for the range of cooling rates in the present experiments of $2.50 \times 10^{-4}$ to $6.7 \times 10^{-4}$ $\mathrm{deg} / \mathrm{s}$ (see Table I) when the initial supercooling is large. For small initial supercoolings $\left(\Delta \mathrm{T}_{\mathrm{n}}<0.1 \mathrm{deg}\right)$, the data points in Figure 8 show notable scatter. One cannot be sure, however, whether this scatter was caused by the salinity of the water, the rate of cooling, or just by experimental error. Obviously more and better controlled experiments will be necessary to clarify this point.

Before concluding this section, it should be added that because of the large number of data points for low $\Delta T_{n}$ values, when Equation (23) was fitted to the data points, the data points for $\Delta \mathrm{T}_{\mathrm{n}}<0.1$ were given a smaller weighting in inverse proportion to their number over the range of $\Delta T_{n}=0.0$ to 0.1 .

\section{CONCLUSIONS}

From the study reported in this paper, one learns that the formation of frazil in supercooled water in the initial period follows well-defined functional trends, regardless whether the water is saline or fresh and whether the saline water is natural or is artificially prepared by dissolving "Forty Fathoms" in distilled water.

The average rate of frazil production in the initial period is a sensitive function of the initial supercooling of the water, or the supercooling of the water at seeding. For the experimental salinity range of the present study of $11.45 \%$ to $48.1 \%$, a well-defined functional relationship was found between the average production rate and the initial supercooling for the formation of saline frazil and salinity was found not to be an important parameter affecting this relationship. For distilled-water frazil, a different relationship between production rate and initial supercooling was obtained. Under the same initial supercooling conditions, frazil will form at a faster rate in fresh water than in saline water. Further experiments are needed to study the change of production rate of frazil when the salinity of the water changes in the range of zero to $11.45 \%$ oo.

When expressed in normalized form, the concentration of frazil in both saline and fresh water formed at different initial supercoolings was found to be a reasonably well-defined function of the normalized time alone. Thus, using the normalized concentration versus normalized time relationship obtained experimentally from this study, one is able to predict the concentration of frazil in water at any given time regardless of the salinity and the initial supercooling of the water if a certain design error is acceptable.

The rate of production of frazil is a more complicated function of time and is affected both by the degree of initial supercooling and the salinity of the water. The curves for normalized production rate versus time are found to be either single peaked or double peaked. It is theorized that the production rate curve of a given type of frazil crystal is always bell shaped and single peaked. The height and the spread of the peak change as the salinity and the initial supercooling of the water change. More than one kind of frazil crystal can be formed simultaneously in the water. When this happens, the production rate curve of the supercooling water will be the sum of the individual production-rate curves. The production of one or more than one type of frazil crystals in the water and the modification of the height and spread of the curves because of changes in salinity and initial supercooling thus can easily explain the shapes of the production curves obtained from the present study.

There are several characteristic parameters that are important in specifying the production of frazil and in normalizing the frazil production relationship. They are the initial supercooling at seeding $\Delta \mathrm{T}_{\mathrm{n}}$, the maximum temperature depression $\Delta \mathrm{T}_{\mathrm{min}}$, the time from seeding to $90 \%$ maximum temperature-depression recovery $t_{c}$, and the 
concentration of frazil at this characteristic time $\bar{c}_{i c}$. From analyzing the experimental data, it was found that

1. $\Delta \mathrm{T}_{\min }$ was a function of $\Delta \mathrm{T}_{\mathrm{n}}$ alone, regardless of the salinity of the water, and in the case of saline water, regardless of whether the sea-water was natural or was artificially prepared by dissolving "Forty Fathoms" in distilled water. An empirical equation relating $\Delta \mathrm{T}_{\min }$ and $\Delta \mathrm{T}_{\mathrm{n}}$ was derived by fitting a curve to the data points using the method of least squares.

2. For the salinity range of $11.45 \%$ to $48.1 \%$ of the present experiments, $t_{c}$ was found to be a function of $\Delta T_{n}$ alone and this relationship was not affected by the salinity of the water. For distilled water, the $\mathrm{t}_{\mathrm{c}}-\Delta \mathrm{T}_{\mathrm{n}}$ relationship, although it was of the same form, was different. Further work will be needed to study the change of the $t_{c}-\Delta T_{0}$ relationship as salinity
changes from zero to $11.45 \%$.

3. $\bar{c}_{i c}$ was a function of $\Delta T_{n}$ alone regardless of the salinity of the water and the nature of the water (i.e., whether it was genuine or was artificially prepared from "Forty Fathoms"). Large scatter of the experimental data was observed for $\Delta T_{n}<0.1$. However, it was not certain whether the scatter was systematic or was caused by experimental error.

Further work to continue the present study probably should be on one hand the physical modelling of the production of frazil and on the other, the derivation of empirical equations for the concentration and the rate of production of frazil as functions of time. For the former, microscopic study of the frazil crystals and the study of the thermodynamics involved in the growth of the ice crystals should be looked into. For the latter, much better controlled experiments will be needed, especially on the control of the seeding of the supercooled water. The future study, of course should include the important salinity range of zero to 11.45
\% oo.

\section{ACKNOWLEDGEMENTS}

The authors wish to thank Messrs Jesse Heidt and Brian Trapp, both research technologists at National Water Research Institute, for the former's assistance in conducting the laboratory experiments and for the latter's assistance in analyzing the experimental data, including the plotting of graphs and fitting of curves to experimental data using a microcomputer.

\section{REFERENCES}

Dorsey, N.E. 1940. Properties of ordinary water-substance in all its phases: water-vapor, water, and all the ices. New York, Reinhold Publishing Corporation. (American Chemical Society. Monograph Series, No. 81.)

Hanley, T. O'D., and Tsang, G. 1984. Formation and properties of frazil in saline water. Cold Regions Science and Technology, Vol. 8, No. 3, p. 209-21.

Martin, S. 1981. Frazil ice in rivers and oceans. Annual Review of Fluid Mechanics, Vol. 13, p. 379-97.

Martin, S., and Kauffman, P. 1981. A field and laboratory study of wave damping by grease ice. Journal of Glaciology, Vol. 27, No. 96, p. 283-313.

Osterkamp, T.E. 1978. Frazil ice formation: a review. Journal of the Hydraulics Division, American Society of Civil Engineers, Vol. 104, No. HY9, p. 1239-55.

Tsang, G. 1982. Frazil and anchor ice: a monograph. Ottawa, National Research Council of Canada. Associate Committee on Hydrology. Sub-committee on Hydraulics of Ice Covered Rivers.

Tsang, G. 1983. Formation and properties of frazil formed in seawater at different supercoolings. [POAC 83.] The seventh International Conference on Port and Ocean Engineering under Arctic Conditions, Helsinki, Finland, 5-9 April 1983. [Proceedings], Vol. 3, p. 222-41. (VTT Symposium 37.) 